\title{
AN EXPERIMENTAL ANALYSIS OF TRANSLUCENT CONCRETE BLOCK BY USING RESIN
}

\author{
SUHOTRA GUPTA ${ }^{1}$, SOHIT AGARWAL ${ }^{2} \&$ MUKESH PANDEY ${ }^{3}$ \\ ${ }^{I}$ Scholar, CE Department, ITM University Gwalior, India \\ ${ }^{2}$ Assistant Professor, CE Department, ITM University Gwalior, India \\ ${ }^{3}$ Professor, CE Department, ITM University Gwalior, India
}

The main reason and principle to study this research work to find the amount of light which can able to pass through the resin concrete block, which help the building from artificial energy consumption and maximum use of natural sunlight during day time, it is done by the help of Lux meter, and noticed that lumen of light increases as resin strip percentage increases. This resin translucent block is formed by cement, river sand and resin which is casted in strips and inserted into the block during casting. The size of the block carried out for experimental work is $150 \mathrm{~mm} \times 150 \mathrm{~mm} \times 150 \mathrm{~mm}$ as per IS code 2185.1:2005. In this resin translucent concrete block other experiment like compressive strength is also conducted and noticed that by increasing the percentage of resin strips $(0.6 \%, 1.2 \%$, and $1.8 \%)$, compressive strength also increases with respect to control specimen. Ultrasonic pulse velocity test is also conducted and noticed that concrete quality grading is medium by using different percentage of resin strips $(0.6 \%, 1.2 \%$, and $1.8 \%)$ as per IS code 13311.1 .1992 as compared to control specimen. Water permeability test is also conducted and noticed that the by using different percentage of resin strips $(0.6 \%, 1.2 \%$, and $1.8 \%)$ is poor with compared to control specimen having $0 \%$ resin strips. Therefore it can be that this block can be used for green building where light consumption can takes place and also used for load bearing wall in construction industry.

KEYWORDS: Resin strips, Translucent Concrete, Good Aesthetic View, Artificial Light Consumption, Good Compressive Strength \& Good Water Permeability
\end{abstract}

Received: Jun 06, 2020; Accepted: Jun 26, 2020; Published: Aug 07, 2020; Paper Id.: IJMPERDJUN2020672

\section{INTRODUCTION}

Resin based translucent concrete blocks mainly used for load bearing wall and non load bearing partition wall in the green building and it is one of the most newest materials with various types of applications in the construction field, architecture, decoration and even furniture in building construction purposes. It can be imagined that the concrete with the characteristics of being translucent will permit a good interaction and bonding between the construction and its environment, thereby it creates the environment that are better and more naturally lit by the help of resin which is mainly act as a transparent medium through which light can pass easily without any loss of light through it and maximum amount of light can penetrate through the concrete by the help of resin strips which is deeply inserted in the concrete block and it help the minimum use of artificial light and maximum use of sunlight Not only that at the same time as significantly reducing the expenses of laying and maintenance of the concrete that are constructed. In this research work using of resin strips which are arranged side by side on a concrete base leaving the light to pass from one side to the other. Due to the small thickness of these resin strips, they combine with the concrete. Compared with a traditional electric lighting system, and illuminating the indoors with daylight also creates a more beautiful 
and healthy environment for building. It is a combination of the resin strips and fine concrete which consists of sand and cement, combined in such a way that this materials became both internally and externally homogeneous by nature so that it can be handled easily. It was mainly manufactured in different sizes of blocks and used mainly for the decoration purposes. Resin strips have a good light transmission property by which it it is used as the light transmitting medium through which light enters the building easily and minimum use of artificial light takes place and consumption of electricity takes place during day time. There are various types of translucent concrete which is mainly composed of optical fiber which is also acts as a translucent medium through which the light can pass through the concrete block which is used of load and non load bearing wall in the building but optical fiber are very much costly therefore I have decided to replace this optical fiber materials with the resin strips which is mainly casted in rubber tube and later cut into various shapes and sized according, this resin strips are cheaper in rate and also have the good light transmission property by light can pass through easily through the concrete and makes the room light easily and have a good aesthetic view also. We can mainly use this type of resin concrete block in green building.

\section{LITERATURE REVIEW}

\section{Shen Juan and Zhou Zhi (2019)}

In this research paper it has been observed that the researcher used the diameter of the resin cylindrical rod which was 22 $\mathrm{mm}$ and the length was $20 \mathrm{~mm}, 60 \mathrm{~mm}$, and $105 \mathrm{~mm}$ in diameter. The light guide had excellent light transmittance which can be as high as $93 \%$ within the thickness of $100 \mathrm{~mm}$ and the light transmittance is $60 \%$ with the thickness exceeding 100 $\mathrm{mm}$. The compressive strength of the resin translucent concrete block decreased with the increase of content of the resin respectively and when the area ratio was within the $5 \%$, the compressive strength of resin concrete was close to plain concrete.

\section{Shradha Nimbalkar (2019)}

In this research work it have seen that the light-transmitting concrete is an excellent constructional material. It was observed that the compressive strength of translucent concrete is increased by $4 \%$ optical fibres and decreased by $5 \%$ optical fiber but it is also found that when we increased the percentage of the optical fiber from $2 \%$ to $3 \%$, light intensity increased and was high during the time of afternoon. It is also seen that the changes in surface area of concrete block lead to the decrease in the light intensity. Light transmitting concrete gives good aesthetic views to the buildings and is energy efficiently. The cost of light-transmitting concrete is also rather high but cost is justified because of its useful advantages.

\section{Nawaz Shakeel (2019)}

In this research it hass been found that the transmission of light in the block depends upon the amount of plastic optical fibers used. When we increases the number of fibers in a sample the light transmission increase but at the same time rather the compressive strength decreases.

\section{Poornima D (2019)}

In this research it has been studied that the researcher find the compressive strength of light transmitting concrete with 10\% replacement of the cement by silica fume has been increased by $17.13 \%$ than that of conventional concrete and also saw that the compressive strength of light transmitting concrete with 15\% replacement of cement by silica fume has been increased by $22.76 \%$ than that of conventional concrete. The researcher also examined that the split tensile strength of concrete with $10 \%$ replacement of the cement by silica fume increased by the $13.61 \%$ compared to ordinary one. This it can be used 
sufficiently and can helps in the consumption of electricity.

\section{Dr. Ranju Mohan, Pourush Tyagi, Rohit Sharma, Hardik Rajan (2018)}

In this study two types of concrete blocks, namely, made of POF and made of epoxy resin, are casted and tested against the concrete in terms of strength and translucency character. Concrete blocks with various percentages of fibre and epoxy resins in concrete are tested and comes to a conclusion that the average compressive strength of concrete with $0 \%$ POF for 28 days is found $24.22 \mathrm{kN} / \mathrm{mm} 2$ and that with $1 \%, 2 \%, 3 \%$ and $4 \%$ are found $25.26 \mathrm{kN} / \mathrm{mm} 2,23.48 \mathrm{KN} / \mathrm{mm} 2,23.18 \mathrm{KN} / \mathrm{mm} 2$ and $22.82 \mathrm{KN} / \mathrm{mm} 2$ respectively. Next, the average compressive strength of concrete with $0 \%$ epoxy resin for 28 days is found $24.48 \mathrm{kN} / \mathrm{mm} 2$ and that with $0.5 \%$ and $1.8 \%$ are found $24.96 \mathrm{kN} / \mathrm{mm} 2$ and $23.48 \mathrm{KN} / \mathrm{mm} 2$. Compressive strength for both plastic optical fibre and epoxy resin concrete blocks has been measured by performing compressive testing machine and is found that of conventional concrete. It is seen that slight addition of POF or epoxy resin caused a slight increase in the compressive strength. But successive addition of the POF or epoxy resin causes gradual decrease in compressive strength. Translucency was measured in form of light intensity by Lux meter. As we know that the conventional concrete doesn't pass light, its unit is found to be zero lux. In case of Plastic fibre block, for 1\%, 2\%, 3\% and 4\% fibre used, light transmissivity are found 40 lux, 75 lux, 110 lux \& 122 lux respectively. On the other hand the Epoxy resin block translucency test was conducted both under laboratory and on field. For $0.5 \%$ and $1.8 \%$ epoxy used light transmissivity under laboratory condition are found to be 320 lux and 880 lux. Light transmissivity in the field under sun for $0.5 \%$ and $1.8 \%$ epoxy used light transmissivity under laboratory condition are found to be 880 lux and 1396 lux respectively. The paper shows that the light translucent ability of these concrete block specimen can be utilized in the Green building concept, where aim is to reduce environmental impact.

\section{Aniket Yadav, Shubham Shekhar, Abhishek Anan, Akashdeep Badal, Dr.Bushra Zaman (2018)}

Compressive strength of the translucent concrete decreases with the increase in the percentage of optical fiber. But compressive strength can be improved by adding small proportion of rice husk and steel fiber. POF-based transparent concrete can be used as an art which could be used in museums, commercial buildings, hospitals, and specific exhibitions rather than just a construction material so that the consumption of electricity can takes place.

\section{Shreyas (2018)}

In this research it has been found that there is an $5 \%$ to $10 \%$ increase in initial compressive strength for 7 days \& also increase $10 \%$ to $15 \%$ in initial compressive strength for 28 days to an optical fibers mix up to $3 \%$. But on the other hand the initial \& final characteristic compressive strength gradually decreases with an increase in Optical fibers in the concrete mix. The transparent concrete made with plastic optical fibres finds its applications mainly in partition wall rather than structural element such as columns and beams. The researcher concluded that the Optical fibers can be used in concrete mix up to 5\% replacement will give an excellent results both in strength \& quality aspects.

\section{Dhevam Shah (2018)}

In this research it has been studied that the researcher used optical fibers as it's important basic materials for making to translucent concrete in which they tested the concrete for compressive strength for 7,14 and 28days and found that the $40 \%$ more strength compare to the cube which does not contain optical fibers. They also get that $70 \%$ light transmission using Optical fibers in concrete blocks. 


\begin{abstract}
Abdel Majeed (2016)
In this research it has been studied that the researcher that the compressive strength with the standard concrete mix samples was found to be $26.52 \mathrm{~N} / \mathrm{mm} 2$, and adding POF to the concrete has a variable impact on the compressive strength, and with the greatest improvement $34.16 \mathrm{~N} / \mathrm{mm} 2$ with POF concrete with using fibres of $1.5 \mathrm{~mm}$ diameter spaced $10 \mathrm{~mm}$ apart for a percentage of $1.43 \%$ of fibers, and based on the results of the UPV test in the concrete samples, it is very much clear that the compressive strength of the specimens increased with time. The maximum amount of the light that passing through the cubes was 75.53 LUX using fibers of $1.5 \mathrm{~mm}$ diameter spaces $10 \mathrm{~mm}$ apart for a percentage of $1.43 \%$ of fibers.
\end{abstract}

\title{
Nikhil K (2016)
}

In this research paper it has been seen that the translucent block is used in many ways and implement into many ways and be highly advantageous, in this experiment it is observed that the if the percentage of optical fiber increased then the compressive strength decreases. It can be concluded that the strength of the translucent concrete is inversely proportional to the light transmission of the concrete. Transparent concrete acquires the maximum effects when used in environment with a high degree of light contrast such as this illuminated table in a dimly lit room.

\section{OBJECTIVES AND SCOPE OF THE INVESTIGATION}

\section{A. Objectives}

- $\quad$ To study the compressive strength of resin translucent concrete block.

- To study the water permeability of resin translucent concrete block.

- To study the ultrasonic pulse velocity test of resin translucent concrete block.

- To check the light transmittance of resin translucent concrete block by Lux meter.

\section{B. SCOPES}

Resin translucent block plays an important role in the consumption of electrical energy during day time and utilization of sunlight take place through resin translucent concrete block by which light can penetrate easily and light up the room of the building. This type of concrete block will be used in green building. The possibilities of the resin translucent concrete are innumerable, the more it will be used, the more new uses will be discovered. In the next few more years this resin translucent block surely to be employed in a variety of interesting ways that will be charge the opacity of the construction industry.

\section{EXPERIMENTAL PROGRAM}

\section{A. Ordinary Portland Cement (OPC)}

Ordinary Portland cement is one of the most common type of cement which is widely and commonly used in the constructional purpose. It is the materials which is acts as a binding materials with the fine aggregates to make a homogeneous mixture commonly known as mortar. In this experimental work Ordinary Portland cement of IS Code - IS 8112 : 1989 for 43 Grade Ordinary Portland Cement is used. It is commonly used to construction of bigger structure like building foundation, pile foundation, bridges, tall buildings by which it can withstand heavy load and pressure. In this experimental work for the preparation of resin translucent concrete block using of OPC cement so that quality of the block should be good enough and it should withstand heavy load of the building and commonly used in load bearing wall. 


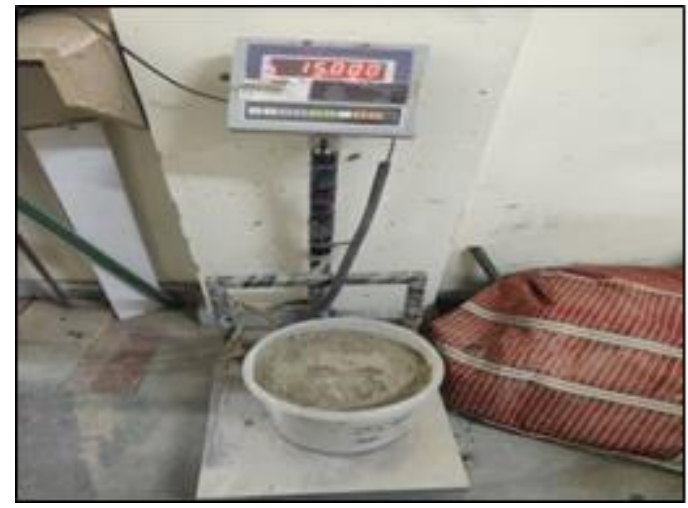

Figure 1: Ordinary Portland Cement

Table 1: Physical Properties of Ordinary Portland Cement

\begin{tabular}{|c|l|l|}
\hline S. No & \multicolumn{1}{|c|}{ Particulars } & \multicolumn{1}{c|}{ Values } \\
\hline 1. & Specific Gravity & 3.15 \\
\hline 2. & Initial setting time & $30 \mathrm{~min}$ \\
\hline 3. & Final setting time & $600 \mathrm{~min}$ \\
\hline 4. & Fineness & $300 \mathrm{~m}^{3} / \mathrm{kg}$ \\
\hline 5. & Fineness modulus & $2-7 \%$ \\
\hline
\end{tabular}

\section{B. Fine Aggregates}

Fine aggregate is one of the most important ingredients which is commonly used in the preparation of mortar, which makes a homogeneous compound and used for the manufacture of resin translucent concrete block. In this experiment using of river sand which is commonly available in the market and also cheaper in rate. This sand is comes under Zone- I.

Table 2: Physical Properties of Fine Aggregate(River Sand)

\begin{tabular}{|c|l|c|}
\hline S. NO & \multicolumn{1}{|c|}{ Particulars } & Values \\
\hline 1. & Fineness Modulus & 2.8 \\
\hline 2. & Specifc Gravity & 2.64 \\
\hline 3. & Water Absorption & 1.46 \\
\hline 4. & Bulk Density & $1.74 \mathrm{Kg} / \mathrm{Lt}$ \\
\hline
\end{tabular}

Table 3: Sieve Analysis of River Sand

\begin{tabular}{|c|c|c|}
\hline S No: & Is Sieve Designation & \% of Passing Obtained \\
\hline 1. & $10 \mathrm{~mm}$ & 0 \\
\hline 2. & $4.75 \mathrm{~mm}$ & 64 \\
\hline 3. & $2.36 \mathrm{~mm}$ & 82 \\
\hline 4. & $1.18 \mathrm{~mm}$ & 127 \\
\hline 5. & $0.600 \mathrm{~mm}$ & 205.5 \\
\hline 6. & $0.300 \mathrm{~mm}$ & 342.5 \\
\hline 7. & $0.150 \mathrm{~mm}$ & 150.5 \\
\hline 8. & Pan & 28.5 \\
\hline \multicolumn{2}{|c|}{} \\
\hline
\end{tabular}




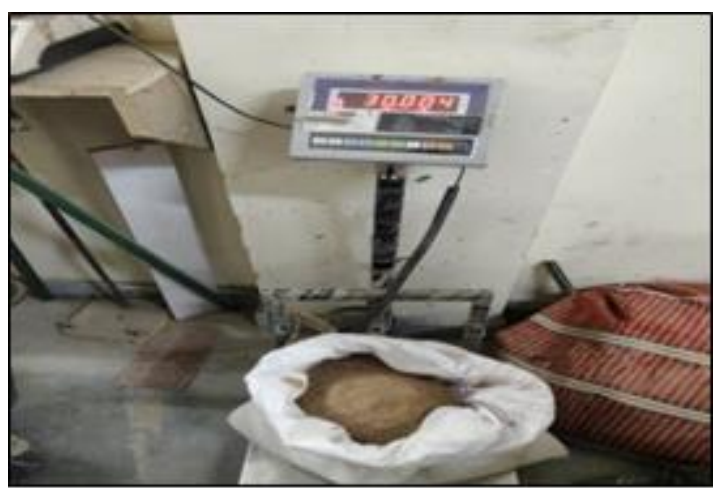

Figure 2: IS Sieve 4.75 mm Passed River Sand.

\section{Resin}

Resin is one of the most important materials that are used for the manufacture of the translucent concrete block. Resin plays an important role in the transmission of light through the concrete block as resin is transparent is colour by which sunlight can easily penetrate through the resin strip medium which helps the building for the minimum use of artificial light and maximum use of natural sunlight which helps the consumption of energy, on the other hand this resin medium also does minimum loss of light energy when this natural light penetrates through the resin strips. Resin is a transparent viscous liquid which is added with a liquid hardner to make resin strips which is casted in water level tube of 50mm diameter, when this resin hardened up after that this strips are cut into desired sizes which is used for the casting of concrete block. The grade of Resin which is used in this experiment is Lapox B-47 Resin and Curing Hardner AH-713.

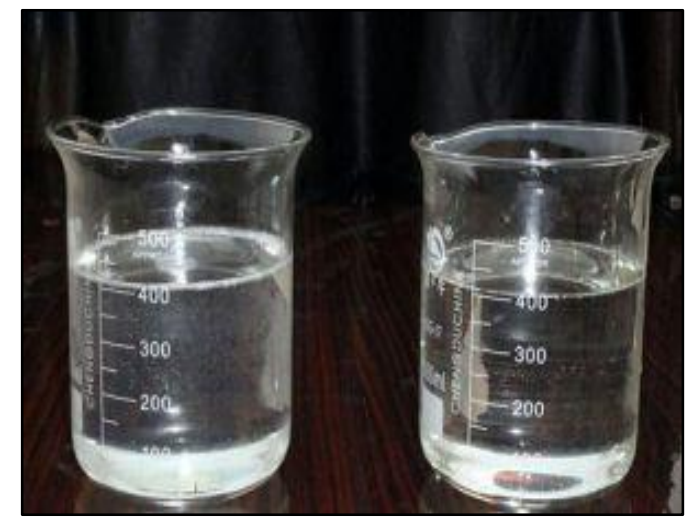

Figure 3: is Lapox B-47 Resin and Curing Hardner AH-713.

Table 4: Physical Properties of Resin and Curing Hardner

\begin{tabular}{|c|l|c|c|}
\hline S. No & Description & Resin (Value) & Hardner (Value) \\
\hline 1. & Colour & Clear liquid & Yellowish brown \\
\hline 2. & Viscosity & $450-650$ & $500-1000$ \\
\hline 3. & Density & $1.15-1.17$ & $0.96-0.98$ \\
\hline 4. & Specific Gravity & 1.8 & $1.08-1.10$ \\
\hline
\end{tabular}

\section{D. water}

Water is one of the most important and key ingredients which when mixed with the cement forms a paste that binds the aggregates together and also maintain the water cement ratio and helps in the workability of the cement mortar paste. Portable water which is easily available in the laboratory are used for casting of all the specimen of resin translucent concrete block 
of desired shape and size.

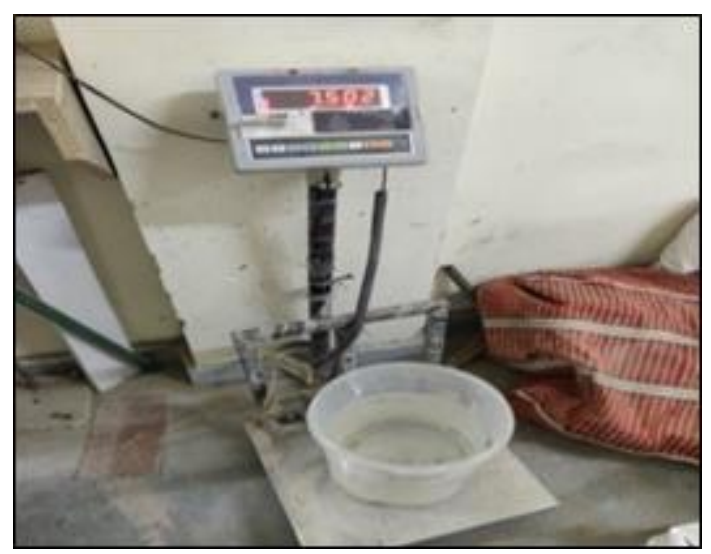

Figure 4: Fresh Portable Water.

\section{METHODOLOGY OF RESEARCH}

\section{A. Preparation of Mould for Casting}

It is one of the most important process for the making of resin translucent concrete block, the first steps involved is preparation of mould in which the concrete will be casted. The mould required for the prototype for the making of block should be made up of various types of easily available material like either tin, wood, plywood. In this research work $150 \mathrm{~mm}$ $\mathrm{x} 150 \mathrm{~mm} \times 150 \mathrm{~mm}$ size of ply wooden mould is used in which the cement sand mortar and resin strips is casted for the manufacture of resin translucent concrete block as per IS 456:2000. For the experiment like compressive strength, water permeability, UPSV test of resin translucent mortar concrete block the standard size of block should be $150 \mathrm{~mm}$ x150 mm x150mm as IS:2185.1:2005, IS:3085-1965.

\section{B. Proportioning and Mixing of Materials}

Proportioning and mixing of various types of ingredients for the preparation of materials that will be used for the making of block should be proportioned and mixed properly so that the homogeneity should be maintained among the compound. In this research work mix ratio of 1:5 (cement: river sand) is used. The water cement ratio of 0.5 is adopted as per requirement. The materials is mixed thoroughly with proper water cement ratio for the manufacture of the block. Also used various percentage of resin strips in the mortar concrete block according to its weight i.e $0.6 \%, 1.2 \%$ and $1.8 \%$. There are total 32 specimens which is tested in this experiment, 8 specimens for compressive strength test ( 7 days), 8 specimens for compressive strength test(28 days), 8 specimens for water permeability test (28 days), 8 specimens for USPV test(28 days), water absorption test (specimens which is used for water permeability test), efflorescence test and LUX test (specimens which is used for USPV test).

Table 5: Material Calculation by Weight

\begin{tabular}{|c|l|c|}
\hline S. No & Materials & Weight $(\mathbf{K g})$ \\
\hline 1. & Cement & $45 \mathrm{Kg}$ \\
\hline 2. & Sand & $225 \mathrm{Kg}$ \\
\hline 3. & Water & $22.5 \mathrm{Kg}$ \\
\hline 4. & Resin & $0.6 \%, 1.2 \%, 1.8 \%$ by its weight \\
\hline
\end{tabular}



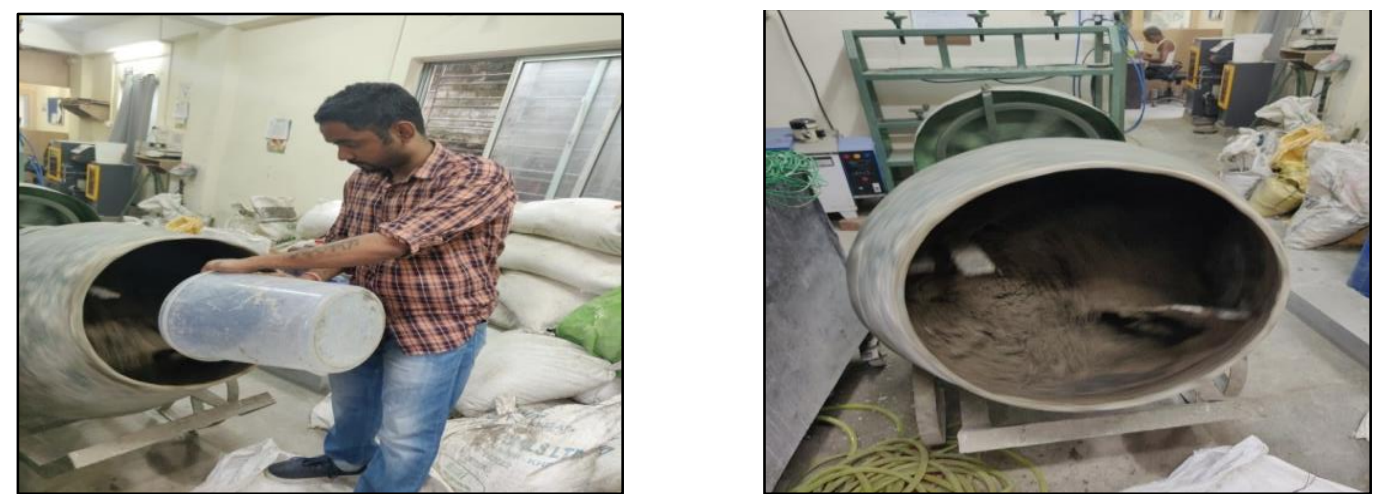

Figure 5: Mixing of Materials in Machine Mixture.

Figure 6: Mixing of Materials in Machine Mixture.

\section{Preparation and Arrangement of Resin Strips in Mould}

Resin plays an important role in this research work, the casting of resin strips also plays a vital role in the preparation of block. The resin and the hardner proportion will be 1:2 ratio. In the making of resin strips first of all the mixture of resin and the hardner is mixed thoroughly in desired proportion otherwise the hardening of the resin strips will not take place properly. The casting of resin will take place by the help of water level tube which is $5 \mathrm{~mm}$ diameter. Filling of resin in this transparent tube with the help of syringe and keep it for 24 hour so that it can gain its strength and hardened enough. After this resin gets hardened, cut the tube into desired length of $160 \mathrm{~mm}$ as the size of the cube is $150 \mathrm{~mm} \times 150 \mathrm{~mm} \times 150 \mathrm{~mm}$ so keep $10 \mathrm{~mm}$ more so that the resin strips can look easily from outside which helps the sunlight to penetrate through this resin strips. After this strips gets cut into desired shape. Peel of the rubber tube from outside with the help of blade, and finally the strips gets ready for its use. The resin strips will kept vertically in the plywood mould during the time of casting of concrete.
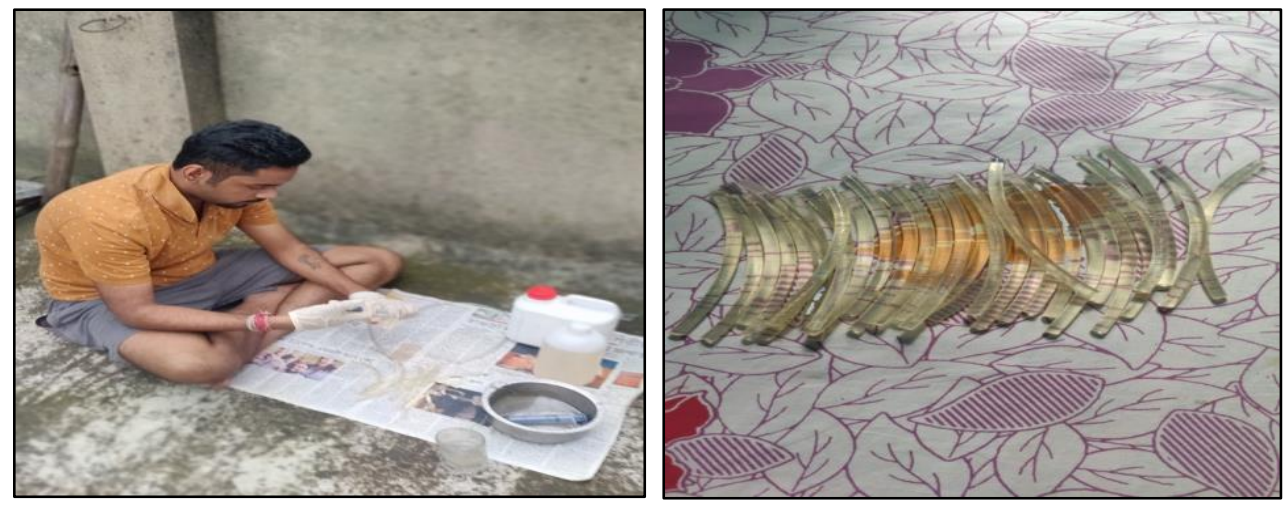

Figure 7: Preparation and Casting of Resin Strips.

Figure 8: Prepared Resin Strips.

\section{Casting and Curing of Concrete Specimen}

The casting of the specimens takes place with the help of cement and river sand, the ratio is 1:5 and water cement ratio will be 0.5 . After proper mixing of this materials the materials is casted in the $150 \mathrm{~mm} \times 150 \mathrm{~mm} \times 150 \mathrm{~mm}$ plywood mould thoroughly. The casting mould is placed over the thermocol and the mixed cements and concrete materials is filled in the mould layer by layers and tamped 15 times thoroughly so that compaction should be good and no voids should be there, filled upto the top of the mould and finish the tops of the mould with the help of trowel. After filling the mould with cement sand concrete hole is drilled with the help of rod and the resin strips is inserted in the mould so that it should touch the thermocol. The distance between the resin strips are according to the ratio of resin strips which is used in various specimen,the 
average distance is $2 \mathrm{~cm}$. The control specimen is also casted with the same materials which is used for the comparison with the resin concrete block. After casting of this blocks marked the block with marker pens so that the block can be identified easily and after that keep the block in room temperature of $20^{\circ} \mathrm{C}$ in 24 hours, then remove the mould from the block thoroughly and put the block in curing tank so that it can gain its strength for 7 days and 28 days respectively so that various test can be conducted.

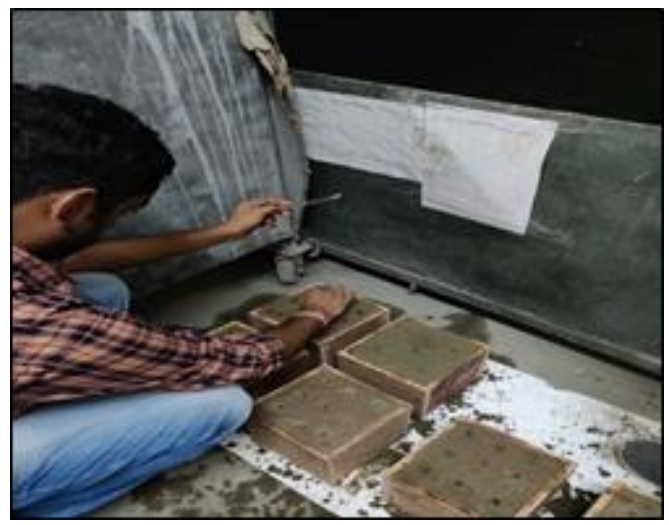

Figure 9: Casting of Resin Concrete Block.

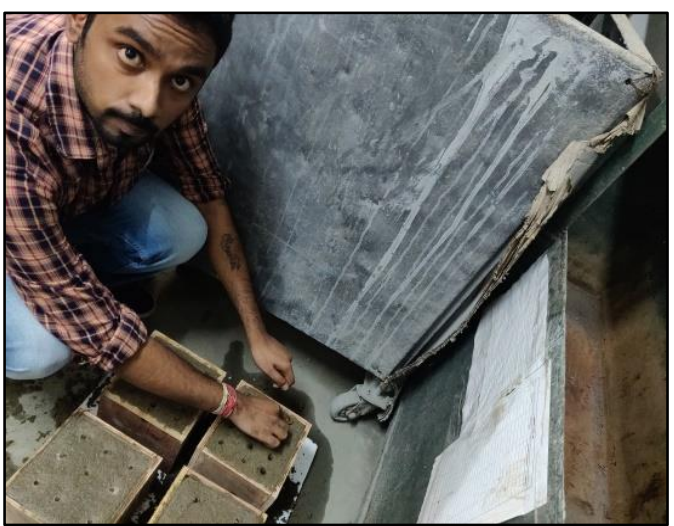

Figure 10: Resin Strips Inserted in Concrete Block.

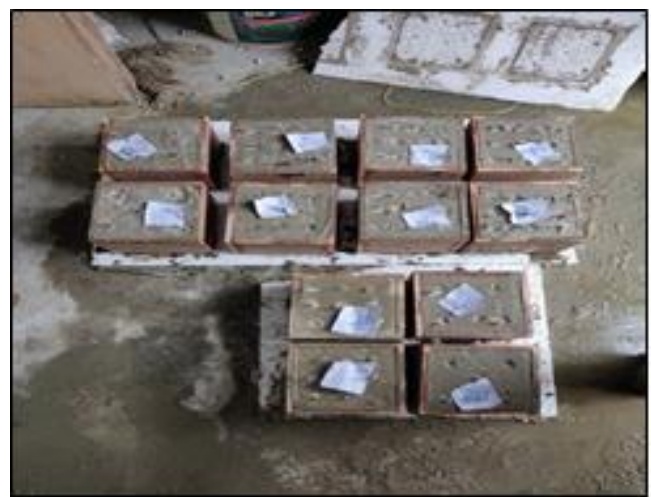

Figure 11: Casting of Resin Translucent Concrete Block. 


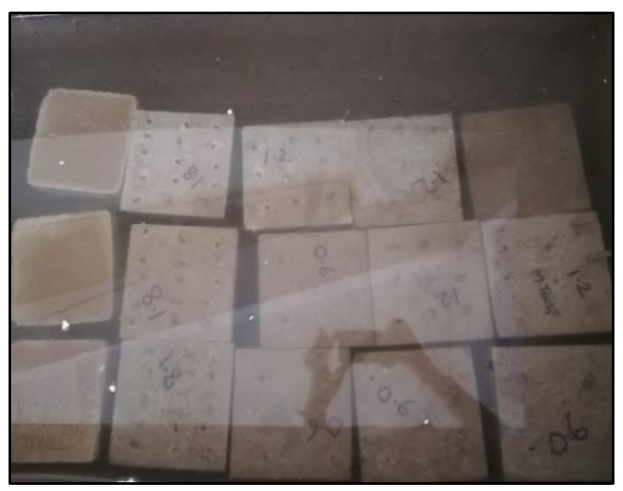

Figure 12: Curing of Translucent Concrete Block.

\section{TESTS, RESULTS AND DISCUSSIONS}

\section{A. Compressive Strength Test}

This is the test which is commonly performed in compressive testing machine (C.T.M). It is already know that concrete is good at compression and weak in tension. In this research work comparison was made between the resin translucent concrete block with cement concrete block which is used as control specimen. In this experimental work different percentage of resin strips in the making of this block and it is observed the result. Test of this samples conducted for 7 days and 28 days and it was noticed that compressive strength of the block increases when percentage of resin strips increases. Therefore resin can be used for the manufacturing of the concrete block. As we know that according to IS:2185.1:2005 table no: 2, clauses $(5.1,5.2,9.4)$ the compressive strength of solid and hollow block for load bearing wall should be min between $4-5 \mathrm{~N} / \mathrm{mm}^{2}$ and in the experiment it is found that compressive strength is more that this permissive limit so it can be easily used for load bearing wall.

Table 6: Compressive Strength in 7 Days

\begin{tabular}{|c|c|}
\hline Specimen & $\begin{array}{c}\text { Compressive Strength in 7 Days } \\
\text { (N/mm2) }\end{array}$ \\
\hline Control Specimen & 3.2 \\
\hline 0.6\% Resin Strips & 3.37 \\
\hline 1.2\% Resin Strips & 4.11 \\
\hline 1.8\% Resin Strips & 3.9 \\
\hline
\end{tabular}

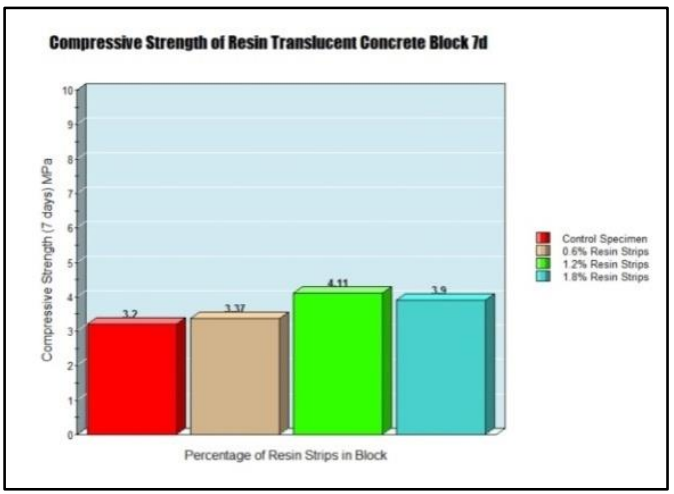

Figure 13: Graph Showing Compressive Strength in 7 Days.

Table 7: Compressive Strength in 28 Days 


\begin{tabular}{|l|c|}
\hline \multicolumn{1}{|c|}{ Specimen } & $\begin{array}{c}\text { Compressive Strength in 28 Days } \\
\text { (N/mm2) }\end{array}$ \\
\hline Control Specimen & 4.44 \\
\hline $0.6 \%$ Resin Strips & 5.63 \\
\hline $1.2 \%$ Resin Strips & 5.75 \\
\hline $1.8 \%$ Resin Strips & 5.78 \\
\hline
\end{tabular}

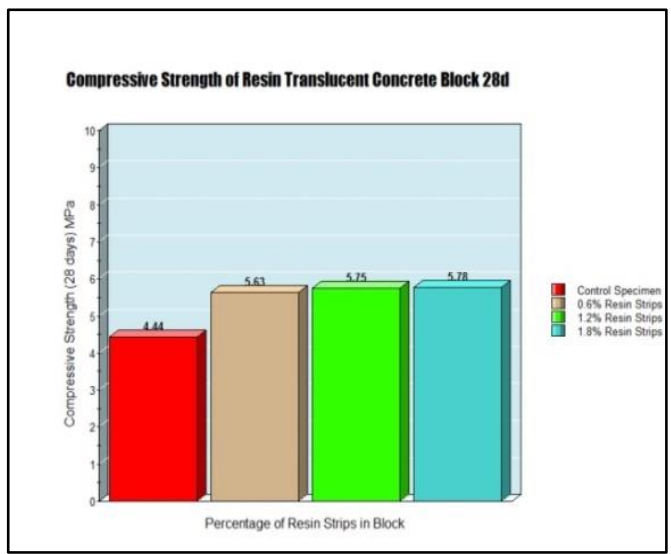

Figure 14: Graph Showing Compressive Strength in 7 Days.

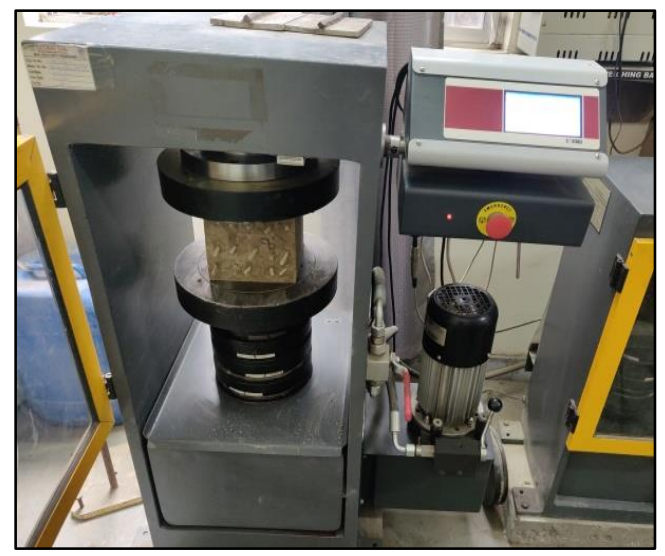

Figure 15: Compressive Strength of Resin Translucent Concrete Block.

\section{B. Water Permeability Test}

This test is conducted to measure the amount of water entering the specimen as well as leaving the specimen. We can also say that it is help to determine the resistance of concrete against water under hydrostatic pressure. In this experiment it is noticed that water permeability for various percentage of resin strips is poor with compare to control specimen. After the study it is observed that resin translucent concrete block is poor in water permeability test. According to IS code 2645:2003 in table no 2 clauses 4.2.1 and 4.2.2 it is mentioned that if the depth of water penetrates the specimen more than $25 \mathrm{~mm}$ then it is not safe for use, as experiment is conducted the depth of water penetration is more in control specimen as well as tested specimen. Therefore this block is not safe where rainfall occurs frequently. Further study is required to minimise the penetration of water into the resin concrete block so that it can be use safely in construction purpose.

Table 8: Compressive Strength in 28 Days 


\begin{tabular}{|l|c|l|}
\hline \multicolumn{1}{|c|}{ Specimen } & $\begin{array}{c}\text { Depth of Water } \\
\text { Penetration }(\mathbf{m m})\end{array}$ & $\begin{array}{c}\text { Protective } \\
\text { Quality }\end{array}$ \\
\hline Control Specimen & $129 \mathrm{MM}$ & Poor \\
\hline $0.6 \%$ Resin Strips & $123 \mathrm{MM}$ & Poor \\
\hline $1.2 \%$ Resin Strips & $107 \mathrm{MM}$ & Poor \\
\hline $1.8 \%$ Resin Strips & $113 \mathrm{MM}$ & Poor \\
\hline
\end{tabular}

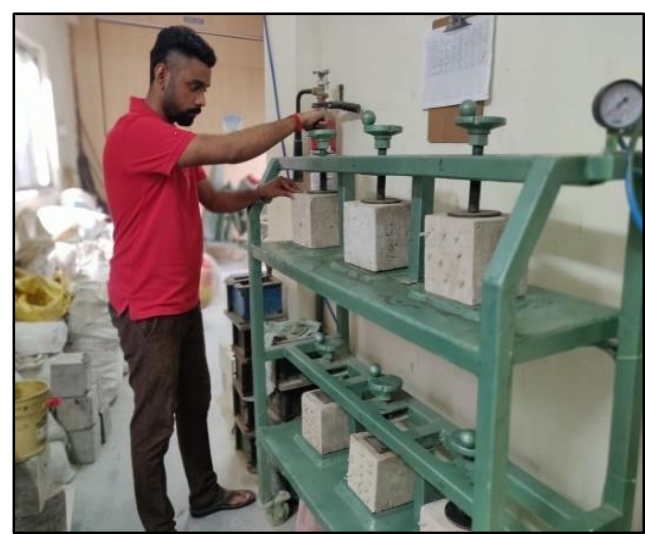

Figure 16: Performing Water Permeability Test of Resin Translucent Concrete Block.

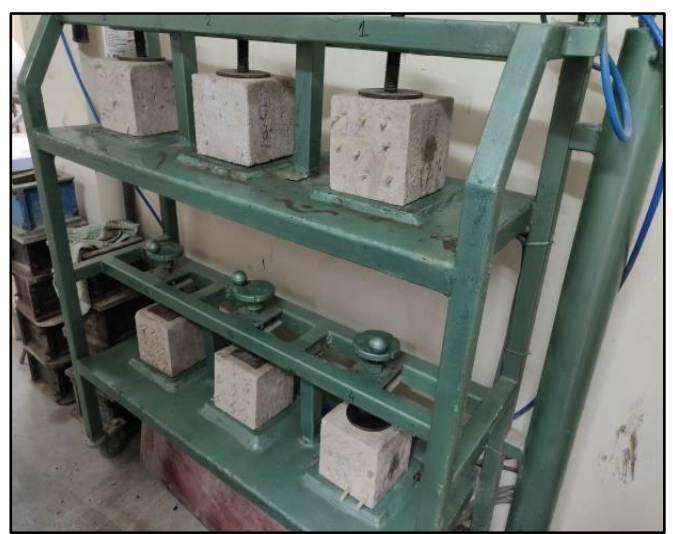

Figure 17: Water Permeability Test of Resin Translucent Concrete Block.

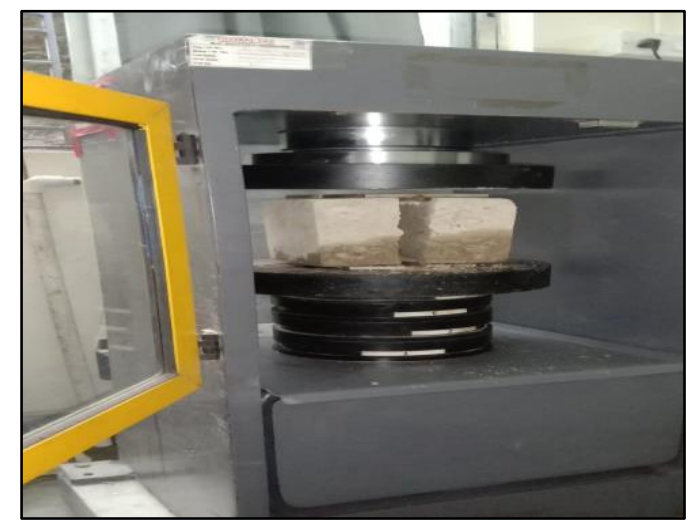

Figure 18: Water Permeability Test of Resin Translucent Concrete Block. 
This experiment is conducted to determine the amount of void that are present inside the resin translucent concrete block specimen. Ultrasonic wave travels only in concrete medium, if the wave does not found concrete medium then it will take more time to receive the wave from source to the receiver. The main objective of this experiment is to determine the homogeneity of the concrete, to find the cracks other fractures present inside the resin translucent concrete block. It is found that this specimen are of medium quality. There are minimum amount of voids, cracks, are present inside the concrete block and it can be reduced by compaction use of fine sand instead of using river sand as per IS code 13311.1:1992, table no 2.

Table 9: USPV Test in 28 Days

\begin{tabular}{|l|c|c|}
\hline \multicolumn{1}{|c|}{ Specimen } & Velocity $\mathbf{~ k m} / \mathbf{s}$ & Quality \\
\hline Control Specimen & 2.5 & Doubtful \\
\hline $0.6 \%$ Resin Strips & 3.2 & Medium \\
\hline $1.2 \%$ Resin Strips & 3.13 & Medium \\
\hline $1.8 \%$ Resin Strips & 3 & Medium \\
\hline
\end{tabular}

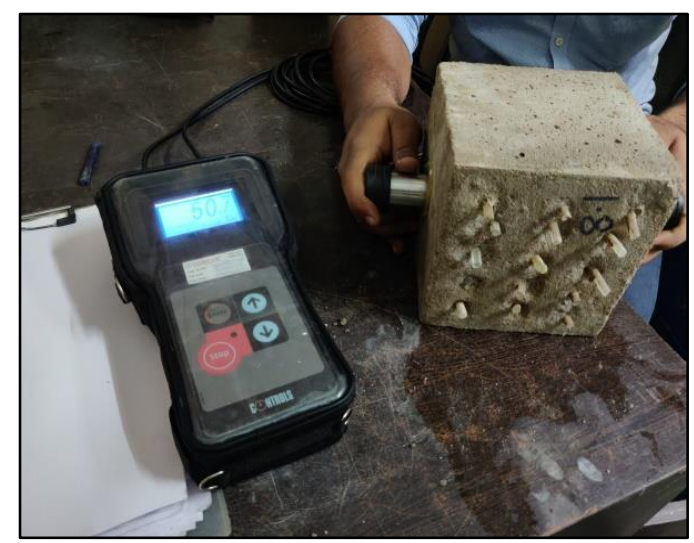

Figure 19: Ultrasonic Pulse Velocity Test of Resin Translucent Concrete Block.

\section{Light Transmittance Test}

This test is one of the most important test that are performed in this experiment. This experiment is totally based on this test. It is done to determine and to observe the amount of light or lumen passes through the resin concrete block so that use of artificial light can be minimised. Lux meter is used and 100W bulb is used to performed this test. Bulb is fixed in a certain distance from the resin concrete block and concrete block is placed between the lux meter and the $100 \mathrm{~W}$ bulb, after that light turned on and reading of the Lux meter is noted to determine the amount of light passing through the $150 \mathrm{~mm}$ per resin concrete block. In this experiment we come to know that intensity of light means lumen increases with increase in percentage of resin strips that are present in the concrete block. Therefore this block can be easily used in green building for the consumption of electricity.

Table 10: Lux Test of Resin Translucent Block by using 100 W Bulb

\begin{tabular}{|l|c|}
\hline \multicolumn{1}{|c|}{ Specimen } & Lux/ 150 $\mathbf{~ m m 2 ~ C u b e ~}$ \\
\hline Control Specimen & 0 \\
\hline $0.6 \%$ Resin Strips & 3 \\
\hline $1.2 \%$ Resin Strips & 7 \\
\hline $1.8 \%$ Resin Strips & 11 \\
\hline
\end{tabular}




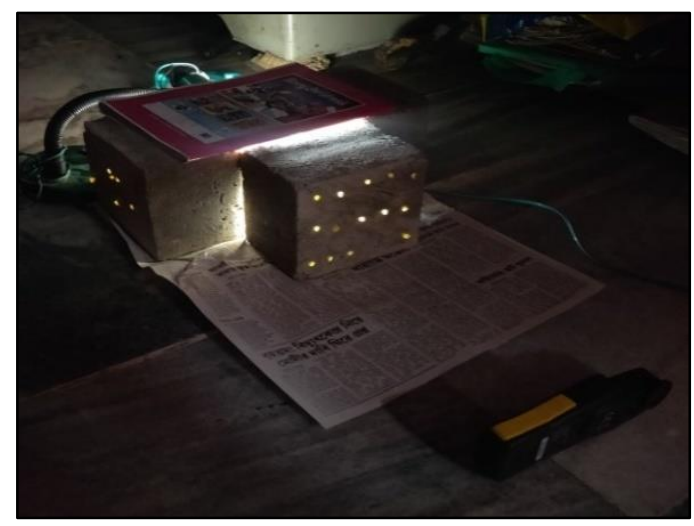

Figure 20: Lux Test of Resin Translucent Concrete Block.

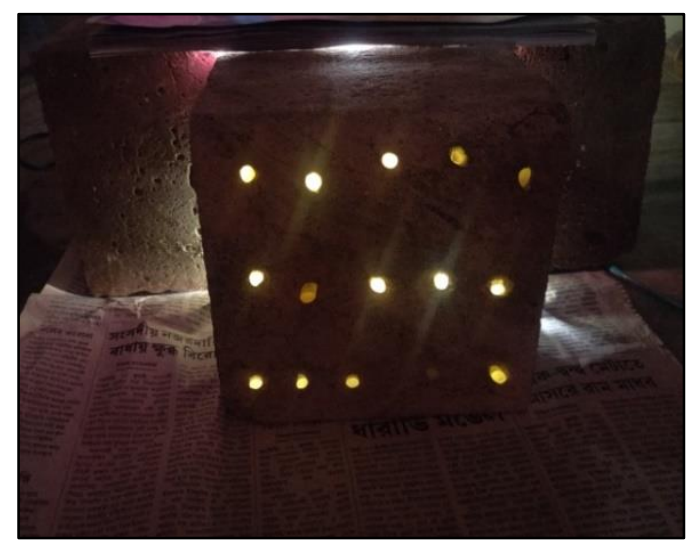

Figure 21: Resin Translucent Concrete Block.

\section{CONCLUSIONS}

From this experimental study it is concluded that this resin translucent concrete block is very much advantageous construction materials. It can be used in the green building to increase the energy efficiency to the structure. It is definitely the future of civil construction material that will be used widely someday as the time will go on. The following conclusion can be drawn on the result of the experimental work.

The light transmittance character of the resin concrete block will increase if the percentage of resin strips is increased in the block by using percentage like $(0.6,1.2$ and 1.8$) \%$.

Compressive strength test results shows that increase in percentage of $0.6,1.2$ and $1.8 \%$ of resin strips also increases the compressive strength. of the resin translucent concrete block.

Water permeability test results shows that water permeability of $0.6,1.2$ and $1.8 \%$ of resin strips is good but not acceptable as compared to controlled specimen.

USPV results shows that due to the presence of resin strips in the block there are certain amount of voids present inside the bloc, it can be reduced by proper compaction during the time of casting of block in the mould.

Resin translucent concrete block required skilled labour for its manufacturing as proper arrangement of resin strips should be provide in the concrete block, as well as the cost of block is little bit high as compared to other block as cost of resin is little bit high. Translucent concrete reduces the dependence on artificial sources of light. Translucent concrete can be used in structure to make them architecturally and aesthetically beautiful, as various types of glowing of resin can be 
made with this type of concrete block.

\section{ACKNOWLEDGEMENT}

With due respect I like to thank all those who have given me the opportunity and helped me to complete these Review Paper work in my M. Tech thesis work. I want to express my gratitude to our Civil Department, ITM University, Gwalior for given me a immense support specially one of our faculty Prof. Sohit Agarwal (Department of Civil Engineering, ITM University, Gwalior). I also want to thank one of the Lab In Charge (Global Lab) in Kolkata where I am done my thesis practical work Mr. Shaswata Mukherjee, and Mr. Devendra Khan, Samsuddin Mollah for their guidance support in the laboratory to complete my experimental work.

Finally, I am grateful to my parents who have supported me from the beginning to complete this work.

\section{REFERENCES}

1. Preparation and Study of Resin Translucent Concrete Products by Shen Juan and Zhou Zhi-Hindawi Advances in Civil EngineeringVolume 2019, Article ID 8196967.

2. A study of Translucent concrete. - Shradha Nimbalkar-International Research Journal of Engineering and Technology (IRJET) e-ISSN: 2395-0056.Volume: 06 Issue: 02 | Feb 2019 www.irjet.net p-ISSN: 2395-0072.

3. Experimental Investigation on Light Transmission and Structural Performance of Translucent Concrete Using 3mm Diameter Plastic Optical Fibers.- Nawaz Shekeel - International Journal of Innovative Technology and Exploring Engineering (IJITEE) ISSN: 2278-3075, Volume-8 Issue-8 June, 2019.

4. Hemanth, R. D., et al. "Evaluation of mechanical properties of e-glass and coconut fiber reinforced with polyester and epoxy resin matrices." International Journal of Mechanical and Production Engineering Research and Development 7.5 (2017): 1320.

5. An Investigating Study on a new Innovative Material:Transparent Concrete. Aniket Yadav, Shubham Shekhar, Abhishek Anand, Akashdeep Badal, Dr.Bushra Zaman. International Journal of Engineering Research andAdvanced DevelopmentVolume 4, Issue 01, DIP: 18.03.06/20180401http://www.ijerad.redmac.in January 2018.

6. Translucent Concrete- Omkar Kadam

7. A study of translucent blocks- Devam Shah- International Journal Of Scientific Research, Education International Journal of Scientific Research 49Volume-7| Issue-5 | May-2018.

8. Mutar, Mohammed Ail, and Noor Mohammed Abdul Hassan. "Synthesis and Characterization Of New Alkyd Resins (Short, Medium And Long) Based On Sunflower Oil And Linoleic Acid As Binder For Paints." International Journal of Chemical \& Petrochemical Technology (2017): 1-16.

9. Experimental Analysis of Translucent

10. Concrete by using Optical Fibers,Nikhil k, Ummer farook $n k$, Silal ahmed ks, Juraige mk, Rameesa saleem,Shabeeba omar, Faculty of Civil Department, RCET Akkikavu, India

11. Student of Civil Department, RCET Akkikavu, India-SSRG International Journal of Civil Engineering (SSRG-IJCE) - volume 3 Issue 3-March 2016.

12. Hussien, Zainab Yousif, and Kadhim Kamil Resan. "Effects of Ultraviolet Radiation with and without Heat, on the Fatigue Behavior of Below-Knee Prosthetic Sockets." International Journal of Mechanical and Production Engineering Research and 
Development (IJMPERD) 7.06 (2017).

13. A study of translucent concrete- Shubham Pundeer-NIT KURUSETRA.2018

14. Department of Civil Engineering, Govt. College of Engineering Amravati, Maharashtra - 444604. IOSR Journal of Mechanical and Civil Engineering (IOSR-JMCE)e-ISSN: 2278-1684,p-ISSN: 2320-334X, Volume 14, Issue 3 Ver. III (May. - June. 2017), PP 18-31.www.iosrjournals.org.

15. Abdel majeed A., Faesal A., Fidelis M. and Jadan M.: Experimental study of light transmitting concrete”,-International Journal of Sustainable Building Technology and Urban Development, vol. 7, issue 3-4 (2016), pp. 133 - 139.

16. Nikhil K (2016) Experimental Analysis of Translucent Concrete by using Optical Fibers. - SSRG International Journal of Civil Engineering (SSRG-IJCE) - volume 3 Issue 3-March 2016.

17. Mahto, Vikas, and Harveer Singh. "Effect of Temperature and Pour Point Depressant on the Rheology of Indian Waxy Crude Oil." International Journal of General Engineering and Technology (2013).

18. Translucent Concrete as the Building Material of the 21St Century Jacek Halbiniak, Paulina SrokaCathedral of the Building and Material Processing Technologies, Czestochowa University of Technology, Faculty of Civil Engineeringul. Akademicka 3, 42-201 Częstochowa, halbiniak@wp.plReceived February 09.2015; accepted February 19.2015.

19. Bhavin K. Kashiyani (2013) A Study on Transparent Concrete: A Novel Architectural Material to Explore Construction Sector,International Journal of Engineering and Innovative Technology (IJEIT) Volume 2, Issue 8, February 2013.

20. A Study on Transparent Concrete: A Novel Architectural Material to Explore Construction SectorBhavin K. Kashiyani, Varsha Raina, Jayeshkumar Pitroda, Dr. Bhavnaben K. Shah-International Journal of Engineering and Innovative Technology (IJEIT)Volume 2, Issue 8, February 2013.

21. Experimental study of light-transmitting concrete

22. Abdel Majeed Altlomate, Faesal Alatshan, Fidelis Mashiri \& Mohamed JadanInternational Journal of Sustainable Building Technologyand Urban DevelopmentISSN: 2093-761X (Print) 2093-7628 Published \online: 07 Nov 2016.

23. Structural Performance of Translucent Concrete Façade Panels-Awetehagn Tuaum, Stanley Shitote, Walter Oyawa, Medhanye Biedebrhan

24. Hindawi Advances in Civil Engineering Volume 2019. 